\title{
THE FUTURE OF ENERGY BIO BATTERY
}

\author{
Urba Ziyauddin Siddiqui ${ }^{1}$, Anand K.Pathrikar ${ }^{2}$ \\ ${ }^{1}$ EC Department, Savitribai Phule Women's Engineering College, Maharashtra, India, urbasiddiqui@gmail.com \\ ${ }^{2}$ EC Department, Savitribai Phule Women's Engineering College, Maharashtra, India, \\ anand_pathrikar@rediffmail.com
}

\begin{abstract}
In today's world Electricity is considered as an integral utility. We can never ever think of our lives without machines. Thus electricity plays a vital role in functioning of the society. One of the portable and convenient sources of this electrical energy is a Battery. Battery is the basic yet most powerful part of any device. Thus a bio battery is an energy storing device that is powered by organic compounds. Bio-Battery generates electricity from renewable fuels providing a sustained, on-demand portable power source. By using enzymes to break down organic compounds, bio-batteries directly receive energy from them. Bio-batteries are alternative energy devices based on bio-electro catalysis of natural substrates by enzymes or microorganisms. This paper brings out an alternative solution to the conventional batteries which is not only a boon to the environment by being eco friendly but also it is an end to worries about non renewable and vanishing sources of energy.
\end{abstract}

Keywords: Bio Fuel Cell (BFC), Electronic Charge Transfer (ECT), Carbon Nano Tube (CNT), Glucose Oxidase (GOX), Department of Defense (DOD).

\section{INTRODUCTION}

A bio-battery is an energy storing device that is powered by organic compounds. Bio-Battery generates electricity from renewable fuels (glucose, sucrose, fructose, etc) providing a sustained, on-demand portable power source. When enzymes in our bodies break down glucose, several electrons and protons are released. Therefore, by using enzymes to break down glucose, bio-batteries directly receive energy from glucose. These batteries then store this energy for later use. This concept is almost identical to how both plants and many animals obtain energy. Bio battery use biocatalyst, either biomolecules such as enzymes or even whole living organism to catalyze oxidation of bio mass-based materials for generating electrical energy. [1]

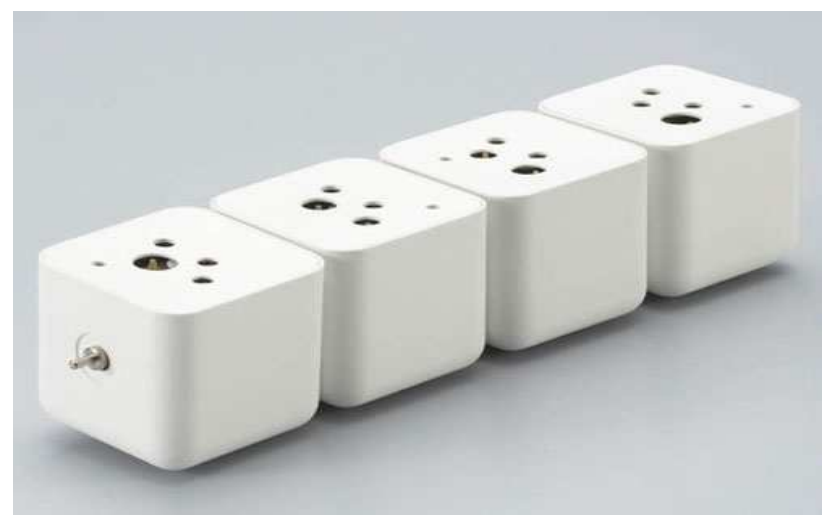

Fig -1: A Bio Battery
Bio Battery can be called as energy accumulated device that is motorized by organic compounds, usually being glucose, like glucose in human blood. Many electrons and protons are released due to break down of glucose by enzymes present in our body. Thus, bio batteries directly get energy from glucose by using enzymes present in a human body break down glucose. An interesting fact is that bacteria can generate electricity when a protein in their cell membranes gets in touch with a mineral surface. Shewanella oneidensis is marine bacteria that can develop electric currents when bared to heavy metals like iron and manganese. These proteins can transmit electrons transversely a membrane at a rate faster enough so that the energy produced is sufficient so that bacteria can survive. Functioning of these bacteria will help scientists in making those bio batteries that could store energy for sensors in remote environment.

Human blood and sugar glucose are considered as most priceless sources of power because they happen naturally, are easy to get and no harmful emissions are reproduced. Another interesting battery uses human urine as its fuel. The size of the device is like a credit card size and might form the source of economical, disposable disease testing kits. What makes it more useful is that the battery and devices for testing is incorporated in one disposable chip [2]

\subsection{Necessity}

There are several reasons to research alternative fuel sources. For one, it may lead to an alternative solution to our dependence on oil and other types of energy sources that harm 
the environment. Also, from a medical point of view, developing small batteries that can be powered by a human body my prove revolutionary for many reasons: health complications/cost/availability. Carbohydrates (glucose) are broken down to release energy and generate electricity. This bio battery, which is based on mechanisms used in living organism, is not only friendly to the environment but also has great potential for use as an energy source.

Unlike fossil fuels, carbohydrates (glucose) are carbon neutral and do not contribute to increases in carbon dioxide. The important constraints like energy density, size/weight, instant recharge, flexible shape, renewable biocatalysts, room temperature operation, and readily available fuel source created the necessity of batteries which can be renewable and a continuous source of energy. The invention of Bio batteries contribute in goodwill of the environment but eliminating the shortfalls offered by traditional batteries made up of metal plates.

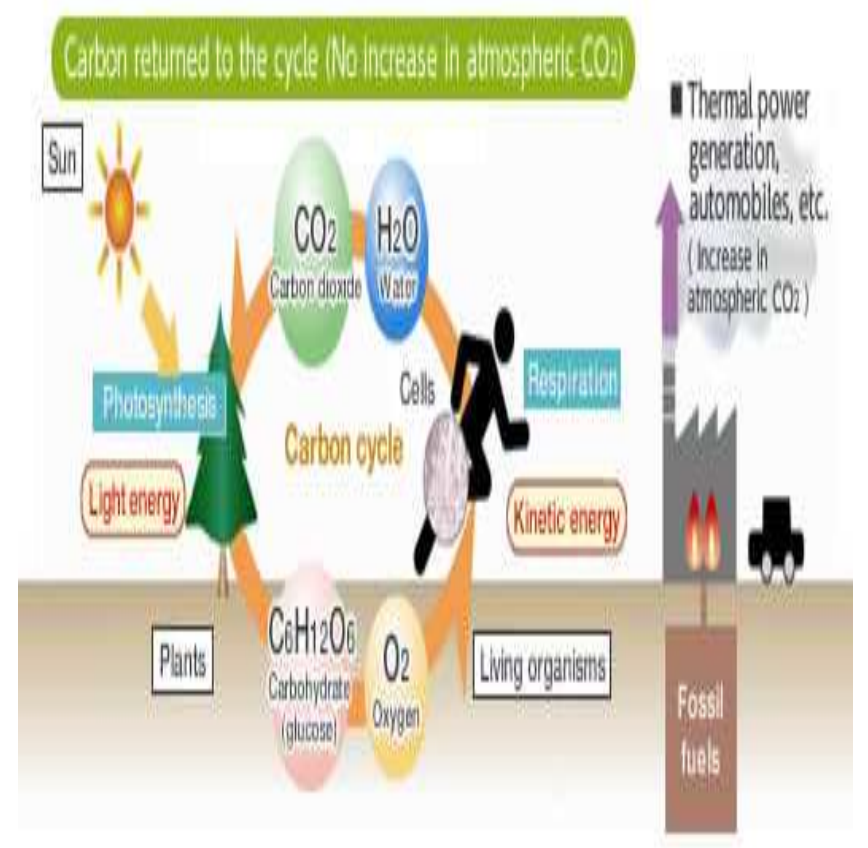

Fig -2: Carbon cycle

Plants create both carbohydrates and oxygen by photosynthesis from carbon dioxide and water. Animals take up those carbohydrates and oxygen and utilize them as an energy source and release carbon dioxide and water. Then this cycle starts again. Since the carbon dioxide is recycled in this system, the amount of carbon dioxide in the atmosphere does not increase. If electrical energy could be directly acquired from this cycle, we could obtain more environmentally friendly energy than that from fossil fuels. Furthermore, renewable energy sources such as glucose (which is present in plants and therefore abundantly available) have an extremely high energy density. Batteries containing heavy metals pose a danger to both the environment and human health. Bio batteries that have been developed in recent years need to be placed in separate compartments for waste separation. But in the near future, it may be possible to completely avoid metals in our batteries.[3]

\subsection{Theme}

Bio battery, which is based on Energy for activity, that is the ATP and thermal energy commonly used in the living organism, can be obtained from the exchange of the electrons and protons through these two enzymatic reactions. To take advantage of this living organism mechanism, the energy for activity from inside the organism must be removed outside the organism as electrical energy. That is, when the electrons and protons move from enzyme to enzyme, it is necessary to extract just the electrons and divert them through a separate path. Thus Sony used an electron transport mediator so that electrons could be exchanged smoothly between the enzymes and the electrodes that are the entrance and exit to that detour. The principles of the bio battery are based on the energy conversion mechanism in living organisms.

However, in order to create the bio battery, several technologies needed to be developed. These include immobilization of enzymes that are normally incompatible with carbon and metal electrodes, electrode structures, and electrolytes. Mechanisms used in living organisms, are not only friendly to the environment but is also likely to be of practical use as an energy source. This prototype bio battery has achieved the world's highest power output of $50 \mathrm{~mW} * 2$.

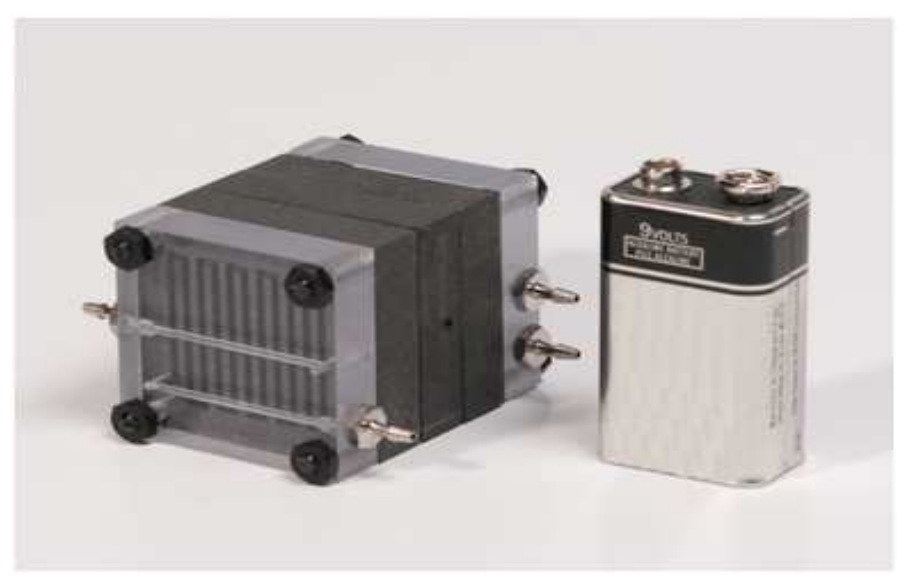

Fig -3: Stacked Bio Battery

There are two types of Bio batteries Passive system type \& Active type system. In passive type system reactive substances are absorbed in to the electrodes through a process of natural 
diffusion. In active type system the reactive substance are introduced by force by technique as string, convection. Biobatteries work similarly to the metabolic process in our bodies, or more specifically the metabolic processes in ruminants and termites that have the ability to digest cellulose. Enzymes break down cellulose into glucose, a central energy source in both animal and plant metabolism and a clean energy source while bio-battery is more environmentally friendly to recycle than metal-based batteries as it creates its own energy from the cellulose found in cardboard and paper.

\section{LITERATURE SURVEY}

\subsection{Introduction}

Electricity, as we already know, is the flow of electrons through a conductive path like a wire. This path is called a circuit. Batteries have three parts, an anode (-), a cathode (+), and the electrolyte. The cathode and anode (the positive and negative sides at either end of a traditional battery) are hooked up to an electrical circuit.

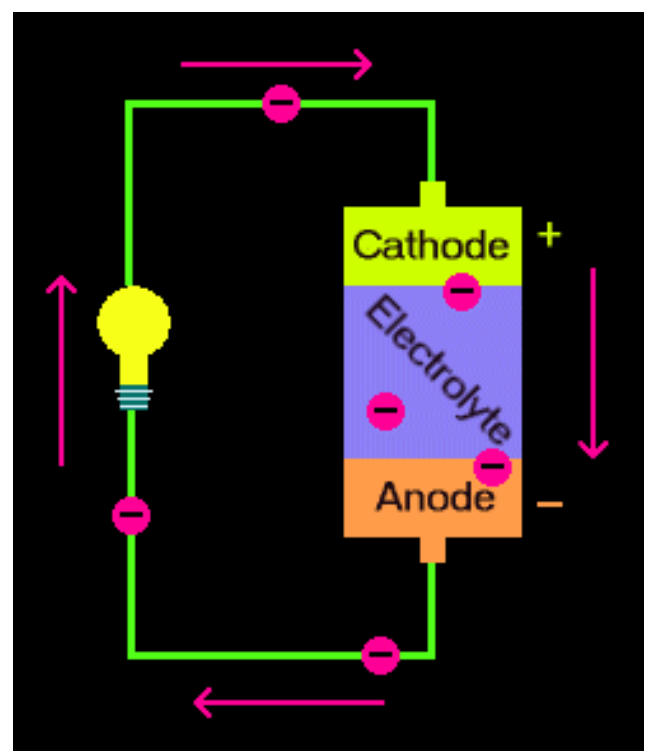

Fig -4: Traditional Battery Principle

The chemical reactions in the battery cause a buildup of electrons at the anode. This results in an electrical difference between the anode and the cathode. You can think of this difference as an unstable build-up of the electrons. The electrons want to rearrange themselves to get rid of this difference. But they do this in a certain way. Electrons repel each other and try to go to a place with fewer electrons.

In a battery, the only place to go is to the cathode. But, the electrolyte keeps the electrons from going straight from the anode to the cathode within the battery. When the circuit is closed (a wire connects the cathode and the anode) the electrons will be able to get to the cathode. In the picture above, the electrons go through the wire, lighting the light bulb along the way. This is one way of describing how electrical potential causes electrons to flow through the circuit. [6]

However, these electrochemical processes change the chemicals in anode and cathode to make them stop supplying electrons. So there is a limited amount of power available in a battery. When we recharge a battery, you change the direction of the flow of electrons using another power source, such as solar panels. The electrochemical processes happen in reverse, and the anode and cathode are restored to their original state and can again provide full power.

\subsection{History}

As an electrical signal can induce a biological reaction; the reverse in is also true in most of the cases and in this way biological processes can be used to generate electricity for powering electrical equipment. Even though the Bio fuel cells have been known for almost a century since the first microbial BFC(Bio fuel cells) was demonstrated in 1912,the first enzyme-based bio-fuel cell was reported only in 1964 using glucose oxidize (GOx) as the anodic catalyst and glucose as the bio-fuel.

\subsubsection{The first Bio Battery:}

The Bio Battery, based on the work of Professor Kenji Kano (Kyoto University), is a type of battery that uses energy sources such as carbohydrates, amino acids and enzymes from a variety of sources. anode consists of sugar-digesting enzymes and mediator, and the cathode composes of oxygenreducing enzymes and mediator. The mediators in this case are Vitamin K3 for the anode and potassium ferricyanide for the cathode. When sugar is added to the mixture, the anode garners the electrons and hydrogen ions. When the battery generates power, the protons travel to the cathode through the electrolyte to combine with the oxygen to produce water. Since the biocatalysts (enzymes) are very selective catalytically, the miniaturized bio-fuel cell could in principle be fabricated as a membrane-less fuel cell.

\subsubsection{The Micro Fluidic BFC:}

Lim and Pal more at the Brown University have reported a micro fluidic BFC with many channels connected in parallel In this configuration, the design allows streams of fuel and oxidant to flow in parallel within a micro channel without using a membrane as a separator and showing a power density $>25 \mathrm{uW} / \mathrm{sqcm}$. Several potential applications of BFCs have been reported or proposed in the literature for implantable devices, remote sensing and communication devices as a sustainable and renewable power source. However, there are no BFC design formats or templates that allow for the 
production of a working device with a size on the order of 1 cc, which are needed for several "real world" applications.

\subsubsection{Enzyme Based Bio Battery:}

Enzyme based BFC is very attractive, however it has been shown that electron flow is too slow to make a viable fuel cell. This is due to the difficulty for enzymes to attain direct electrical contact with the electrodes of the cell and catalyze reactions effectively.

The principles of the bio battery are based on the energy conversion mechanism in living organisms. However, in order to create the bio battery, several technologies needed to be developed. These include immobilization of enzymes that are normally incompatible with carbon and metal electrodes, electrode structures, and electrolytes. Mechanisms used in living organisms, are not only friendly to the environment but is also likely to be of practical use as an energy source. Sony has focused on these advantages since 2001 and has developed an electrical power generation device that uses mechanisms similar to those in living organisms.

\subsubsection{Bio battery using Human Blood}

In 2003, Japanese researchers at Panasonic's Nanotechnology Research Laboratory announced that they were working on extracting power from blood glucose. At the time, they were using enzymes -- a frequent component of bio-batteries due to their catalytic properties -- to retrieve electrons from glucose. Two years later, a different Japanese research team, this one from Tohoku University, announced that they had succeeded in creating a small "biological fuel cell." Their cell could be used to power small medical devices, such as an implant to measure blood sugar levels in diabetics. Future versions of such technology could, like RPI's nanocomposite paper, be used to power an artificial heart with the blood that flows through and around it.

\subsubsection{Bio battery using Human Urine}

In August 2005, scientists in Singapore developed a battery that uses human urine as its fuel. Despite its potentially offputting power source, the battery has a wide variety of applications. The researchers said that their device was the size of a credit card and could form the basis of inexpensive, disposable disease-testing kits. (Urine is already used to detect drugs and some diseases.) What makes the device particularly useful is that it integrated the battery and testing device into one disposable chip. Imagine a one-time use home-testing kit for diseases like cancer or hepatitis. One of the researchers involved in the project said that the battery could also be adapted to provide a brief charge to other electronic devices. A lost hiker might use one to power a cell phone for a short emergency call.[4]

\subsubsection{Bio Battery using Carbohydrates}

Sony Corporation (Japan) has developed a bio-battery with a peak power output of $50 \mathrm{~mW}$, which could power a portable MP3 player. On August 23, 2007 Sony announced the development of a bio battery that generates electricity from carbohydrates (sugar) utilizing enzymes as its catalyst, through the application of power generation principles found in living organisms.

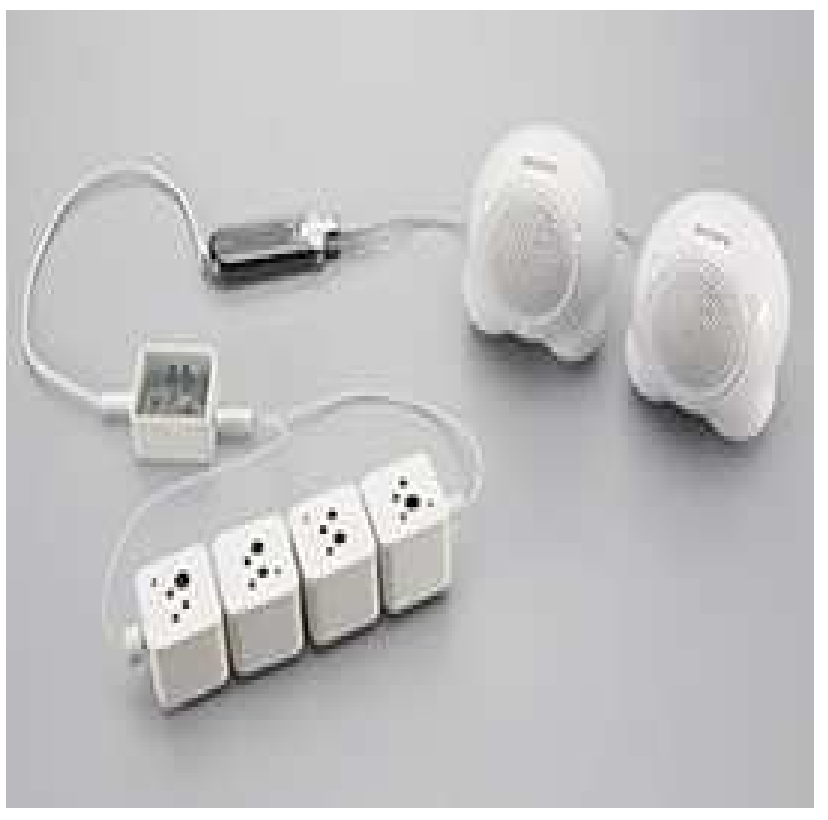

Fig -5: An Mp3 powered by a Bio battery

\subsubsection{Recent Bio Batteries using Blood and Sweat:}

"Its flexible, it can be shaped or folded, \& can poke a hole in it \& it still works" says chemist ROBERT LINHARDT , a member of research team that developed the new bio battery made from paper \& carbon nano tubes working at RENSSELAR POLYTECHNIC INSTITUTE IN NEWYORK, easily implanted directly under the skin unlike metal batteries.

\subsubsection{The Latest Bio Battery using Virus:}

Scientists engineered a virus at the "MIT" that could form a battery 3 times more powerful than those found in gadgets today. PROBLEM: virus can mutate $\&$ can spread by air. So when these batteries run our laptop we really have to watch which virus to remove.

\subsubsection{Bio Battery using Bacteria:}

Bielefeld iGEM team is to develop an environmentally friendly bio-battery (Microbial fuel cell -- MFC), which directly transforms bacteria into energy. Batteries such as these work in the same way as conventional batteries, but with 
one difference. The MFC consists of two separate units, the anode and the cathode components, just like the batteries now in current household use. A partly permeable membrane separates the two areas. In contrast to conventional batteries, however, there are bacteria in the anode area of the bio-battery instead of electrolytes. These break down substrates, in this case glucose, in a metabolic process. This produces electrons that after starting from the anode are finally delivered in an external loop to the cathode. The external circuit is then the one with the battery-powered application, for example, for lights or small motors. In this way, bacteria can produce electric energy. The bio-battery offers an array of advantages. Due to their simple construction they can be used in regions where there is shortage of electricity, for example, such as in developing countries. An advantage that the bio-battery has over other regenerative energy sources, such as solar and wind power is that they are not dependent on the weather. In the case of bio-batteries, the more nourishment the bacteria receive the more energy they produce. What is more, in theory bacteria are an inexhaustible source of energy as they multiply quickly when supplied with substrates.[5]

A new study reveals how bacteria produce electricity when proteins in their cell membranes come into contact with a mineral surface. Scientists have known for some time that a family of marine bacteria known as Shewanella oneidensis, found in deep ocean sediments and soil, can create electrical currents when exposed to heavy metals like iron and manganese

In a study published (March 25,13) in the journal Proceedings of the National Academy of Sciences, researchers show that these proteins can ferry electrons across a membrane at a rate fast enough to produce the energy the bacteria need to survive

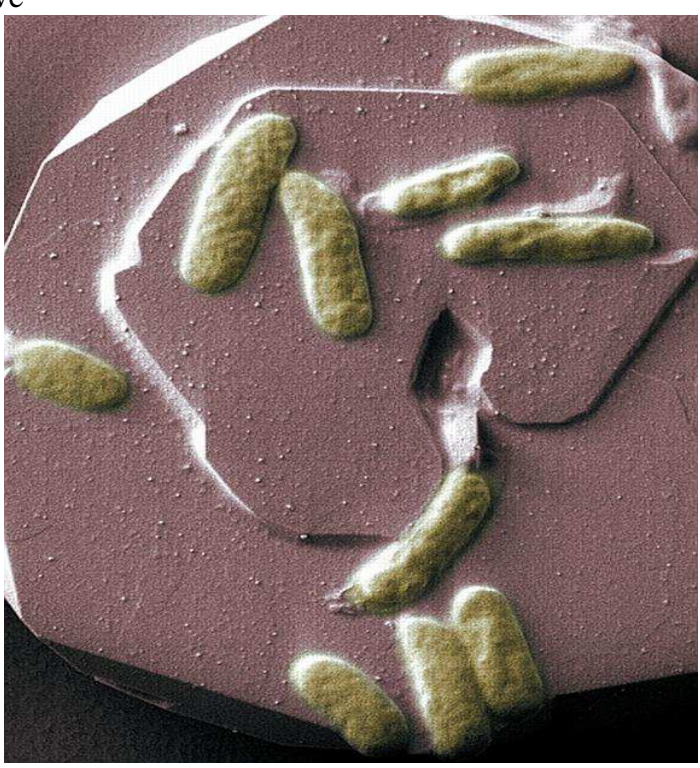

Fig -6: Bacteria that produces electricity
In the laboratory, the Bielefeld students are investigating various bacterial organisms and their genetic components. Through the combination of differing genes it is possible to optimize the organism Escherichia coli with a view to produce electricity more efficiently. The students can already report initial successes: they have isolated various genes that serve to carry the electrons and begun to construct a suitable apparatus for the production of electricity. They would like to have an optimized bio-battery for small-scale use developed by the time the preliminary European round of the iGEM has been decided. Thus on July 17, 2013 technology sights on constructing a bio-battery making use of the bacteria Escherichia coli to convert glucose into energy. [5].

\section{SYSTEM DEVELOPMENT}

\subsection{Introduction}

A bio-battery generates electricity from carbohydrates (sugar) utilizing enzymes as the catalyst, through the application of power generation principles found in living organisms. The bio-battery incorporates an anode consisting of sugardigesting enzymes and mediator, and a cathode comprising oxygen-reducing enzymes and mediator, either side of a cellophane separator. The anode extracts electrons and hydrogen ions from the sugar (glucose) through enzymatic oxidation as follows:

\section{Glucose $\rightarrow$ Gluconolactone $+2 \mathrm{H}++2 \mathrm{e}-$}

The hydrogen ion migrates to the cathode through the separator. Once at the cathode, the hydrogen ions and electrons absorb oxygen from the air to produce

$$
\mathrm{O} 2+4 \mathrm{H}++4 \mathrm{e}-\rightarrow 2 \mathrm{H} 2 \mathrm{O}
$$

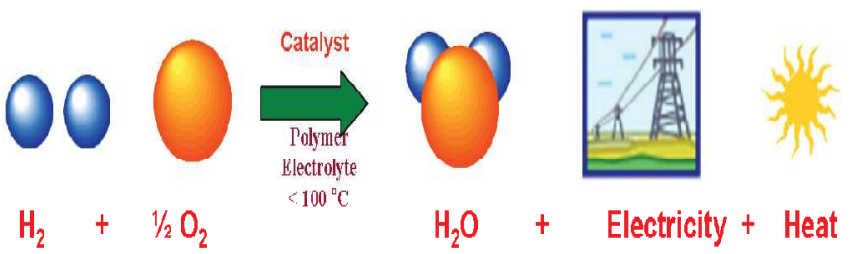

Fig -7: Principle of Fuel Cell

During this electrochemical reaction, the electrons passthrough the outer circuit to generate electricity .It is interesting to note that the catalytic four-electron reduction of oxygen to water could take place at an enzyme electrode in a neutral solution. Due to the selective reactivity of the enzymes at each electrode, no cross reaction occurs between the anode and cathode. In general the Bio batteries could be classified into many types based on fuel containment, fuel and catalyst sources, origin of the catalytic enzymes and the method of electron transfer between reaction site and electrode. [7] 


\subsection{Working}

A Bio-Battery battery consists of two different metals suspended in an acidic solution. They contain an anode, cathode, separator and electrolyte, which are the basic components to any cell battery. Each component is layered on top of another component. Anodes and cathodes are the negative and positive areas on a battery. The anode is located at the top of the battery and the cathode is located at the bottom of the battery.[Anodes are components that allow electrons to flow in from outside the battery, whereas cathodes are devices that allow current to flow out from the battery.

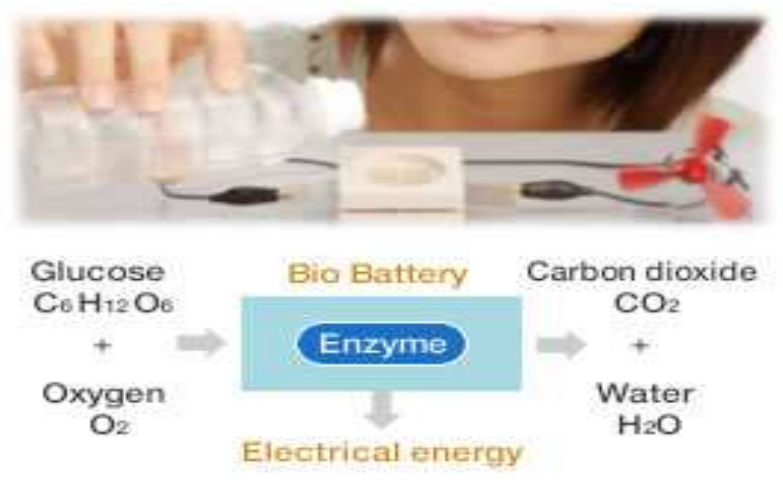

Fig -8: Working of a Bio Battery

Between the anode and the cathode lies the electrolyte which contains a separator. The main function of the separator is to keep the cathode and anode separated, to avoid electrical short circuits. This system as a whole allows for a flow of protons $(\mathrm{H}+)$ and electrons (e-) which ultimately generate electricity. The movement of protons has a moving force that pushes, this movement is called current. When this moving force (current) is measured, it is measured it what is called voltage or volts.

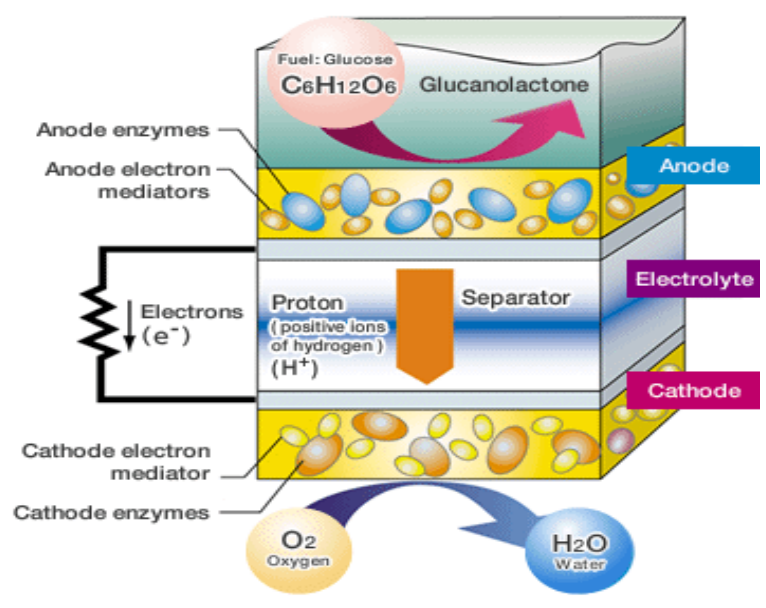

Fig -9: Elements of a Bio battery
Like a conventional fuel cell battery, Bio Battery basically consists of an anode, cathode, electrolyte and separator. However, Bio Battery has certain specific characteristics. First, biological enzymes are used as catalysts for the anode and cathode. Second, enzymes and electronic mediators (which transfer electrons between enzymes, and between enzymes and electrodes) are fixed on the anode and cathode.

Glucose is broken down on the anode side of the battery, producing protons $(\mathrm{H}+)$ and electrons (e-). The protons $(\mathrm{H}+)$ are transferred to the cathode side through the separator, while the electrons (e-) are transported to the cathode side through the mediator, which transfers them to the external circuit. The cathode uses the enzymes to drive an oxygen-reduction reaction which ultimately produces water using both the protons $(\mathrm{H}+)$ and the electrons (e-) transferred from the anode. These reactions at the anode and cathode generate electric energy by creating proton $(\mathrm{H}+)$ and electron (e-) flow in the cell system.

Bio batteries are heavily based on the amount of glucose available. The decomposition of materials to glucose (if they are not already in the proper stage) is the main step in getting the cycle started. Materials can be converted into glucose through the process of enzymatic hydrolysis. Enzymatic hydrolysis is the process in which cellulose (an insoluble substance) is converted to glucose with the addition of enzymes. After glucose exists oxygen and other enzymes can act on the glucose to further produce hydrogen ions and electrons.

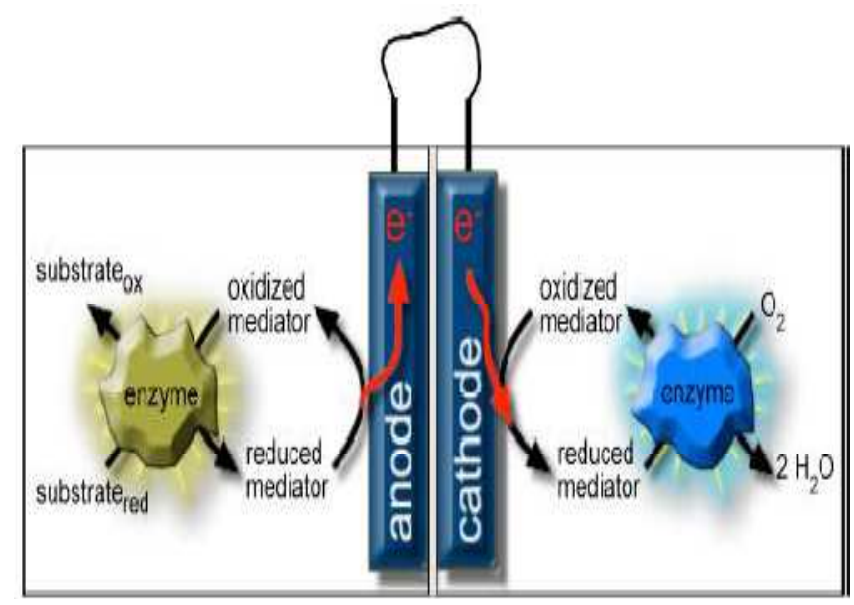

Fig -10: Enzymes used to convert sugar directly into electrical energy 


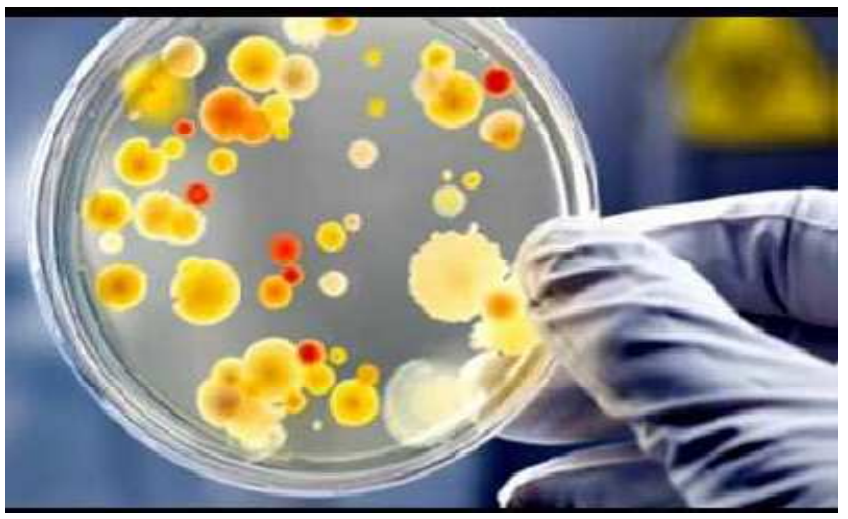

Fig -11: Enzymes extracted from microorganisms

As shown in the above figure Bio battery uses enzymes to convert sugar directly into electrical energy. Enzymes are extracted from microorganisms these enzymes are immobilized in Carbon Nanotube based electrode. Nanocomposite electrodes are integrated with fuel cell hardware.

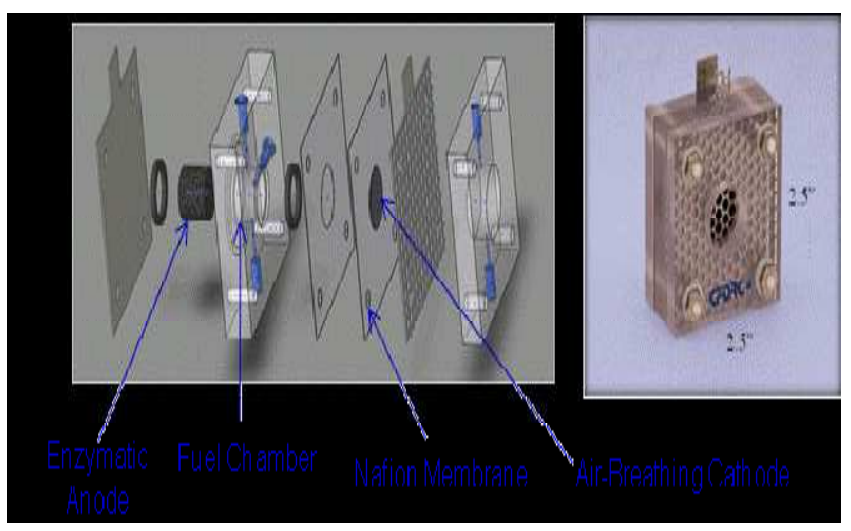

Fig -12: Nanocomposite electrodes integrated with fuel cell hardware

Electron transfer, spatial dislocation of an electron, is the simplest of chemical processes underlying all chemical reactions. The process of efficiently and controllably moving electrons around is one of the primary regulatory mechanisms in biology. of life depends on the constant shuttling of electrons. Almost all chemical reactions involve transfer of electrons and so in principle any one of them can be leveraged for technological applications. The addition of silver has been shown to be an important additive for helping microbes turns sewage into power and to create bio-batteries.

The latest step in the quest for 'clean electricity' has shown that proteins on the surface of bacteria can produce an electric current by simply touching a mineral surface. It is possible for bacteria to lie directly on the surface of a metal or mineral and transfer electrical charge through their cell membranes. In theory, it should be possible to 'tether' bacteria directly to electrodes. With the process, microorganisms attached to the anode then start snatching electrons from organic compounds dissolved in the waste water to produce carbon dioxide and clean water.

All microbe-based batteries and fuel cells need a place to send electrons, a fact that has proved to be technically challenging. With some new research, scientists at Stanford University have replaced bubbling oxygen with a solid silver oxide that consumes electrons, making a more reliable, rechargeable bacterial battery. Silver possesses the highest electrical conductivity of any element and the highest thermal conductivity of any metal. Silver is found in native form, as an alloy with gold (electrum), and in ores containing sulfur, arsenic, antimony or chlorine.

Another advantage with silver it has a high efficiency in terms of the amount of power produced. The downside is that silver is relatively expensive and the cost would be high, should this be reproduced on an industrial scale.

In general, the bio-fuel cells are classified based on the type of electron transfer; mediated electron transfer and direct electron transfer or electronic charge transfer (ECT). The ECT of the bio-fuel cells is critically reviewed and a variety of possible applications is considered. The technical challenges of the biofuel cells, like bioelectrocatalysis, immobilization of bioelectrocatalysts, protein denaturation etc

For the electron transfer the Carbone nano tubes are used which is a tube-shaped material, made of carbon, having a diameter measuring on the nanometer scale. A nanometer is one-billionth of a meter, or about one ten-thousandth of the thickness of a human hair. The graphite layer appears somewhat like a rolled-up chicken wire with a continuous unbroken hexagonal mesh and carbon molecules at the apexes of the hexagons. Carbon Nanotubes have many structures, differing in length, thickness, and in the type of helicity and number of layers.

Although they are formed from essentially the same graphite sheet, their electrical characteristics differ depending on these variations, acting either as metals or as semiconductors. As a group, Carbon Nanotubes typically have diameters ranging from $<1 \mathrm{~nm}$ up to $50 \mathrm{~nm}$. Their lengths are typically several microns, but recent advancements have made the nanotubes much longer, and measured in centimeters

CNTs have unique electronic properties, high mechanical strength and chemical stability, making them attractive for fabricating of GOx coupled CNT based device elements for use in bio fuel cells. For chemically coupling the CNTs with biomolecules, it is critical to functionalize CNT surfaces, 
which are very inert. Several strategies have been develop for functionalizing CNTs for sensing via electrical, electrochemical, and electro-optical means. In all the cases, however, the CNTs are functionalized wet-chemically in a spatially random fashion where molecular bonding is mediated by defect creation, or hydrophobic adsorption.

(a)
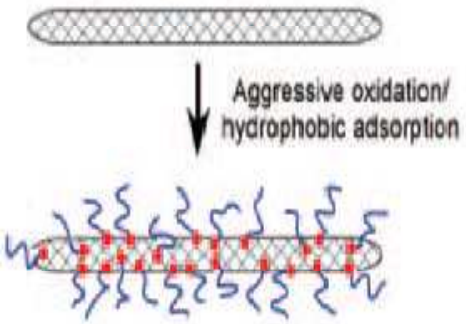

Conventional approach

(b)

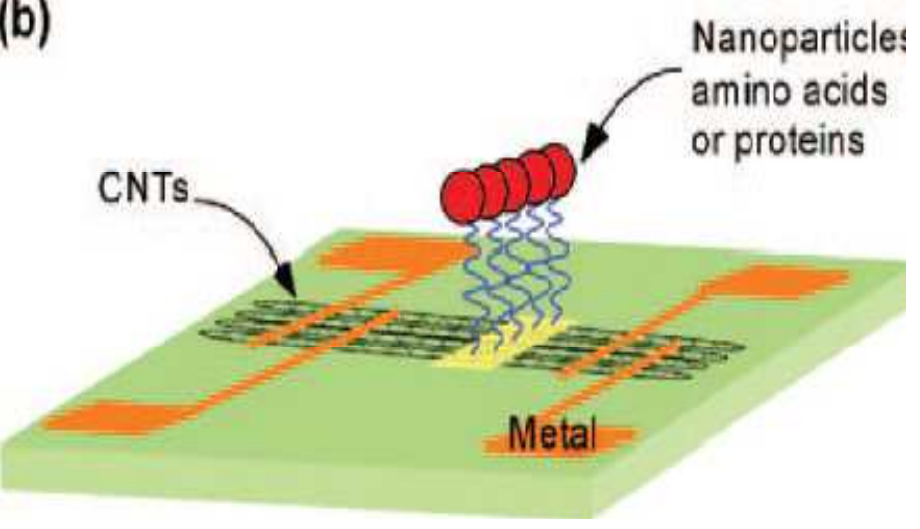

Fig-13:Comparison of random and site-selective functionalization of CNTs, illustrating the utility of latter for nanobiodevices.(a) Conventional methods result in random defect creation, while ion irradiation allows control over site selectivity, defect types, and concentration. (b)Schematic of an example hybrid nanodevice comprised of site-selectively anchored nanostructures on preselected segments of a CNT assembly (black) on a planar substrate (green, e.g., Si). Arrays of such devices, with each array element potentially containing different nanostructures, open up possibilities for addressing specific CNT segments, for fingerprinting, detection, analysis, and separation of biomolecular structures in a single chip.

It is therefore necessary to go beyond the random attachment paradigm to one that allows control over the location of biomolecular attachment in order to fully exploit bioderivatized CNTs to build device architectures on a chip for multifunctional sensing .Localized creation of highreactivity zones in CNTs for subsequent derivatization would ensure that the overall properties of the CNTs are retained or controllably altered, and the integrity of other chip components are not compromised or destroyed during device fabrication.[7]

\subsection{Features \& Specifications}

The bio batteries are stacked in single or a multi cell prototype. The packaging aspects of the bio-fuel cells are also analyzed and the found that relatively little work has been done in the engineering development of bio-fuel cells. The single cell and six cell bio battery packaging is as shown in the figure below

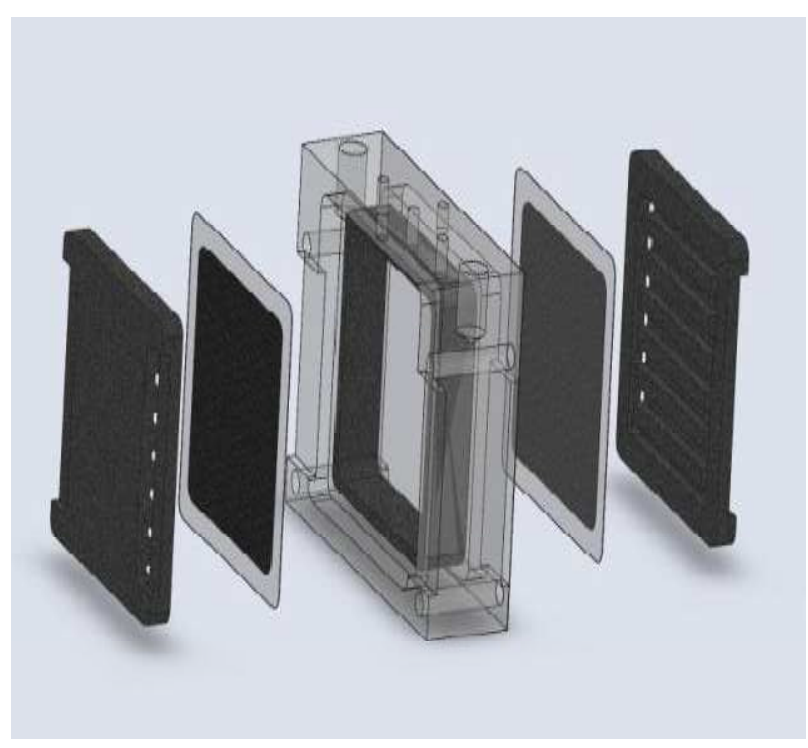

Fig -14: Single Cell Bio battery

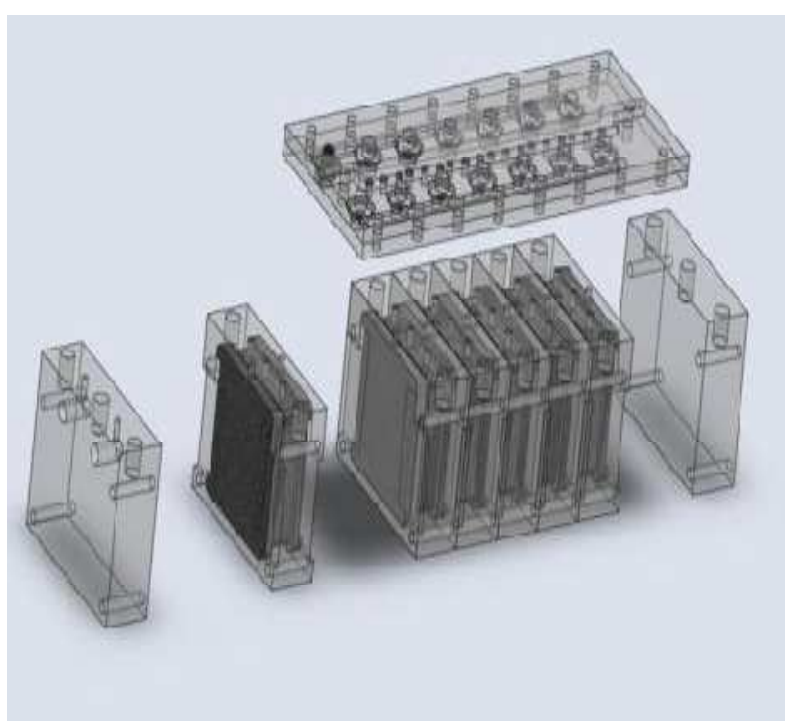

Fig -15: Six Cell Bio battery 

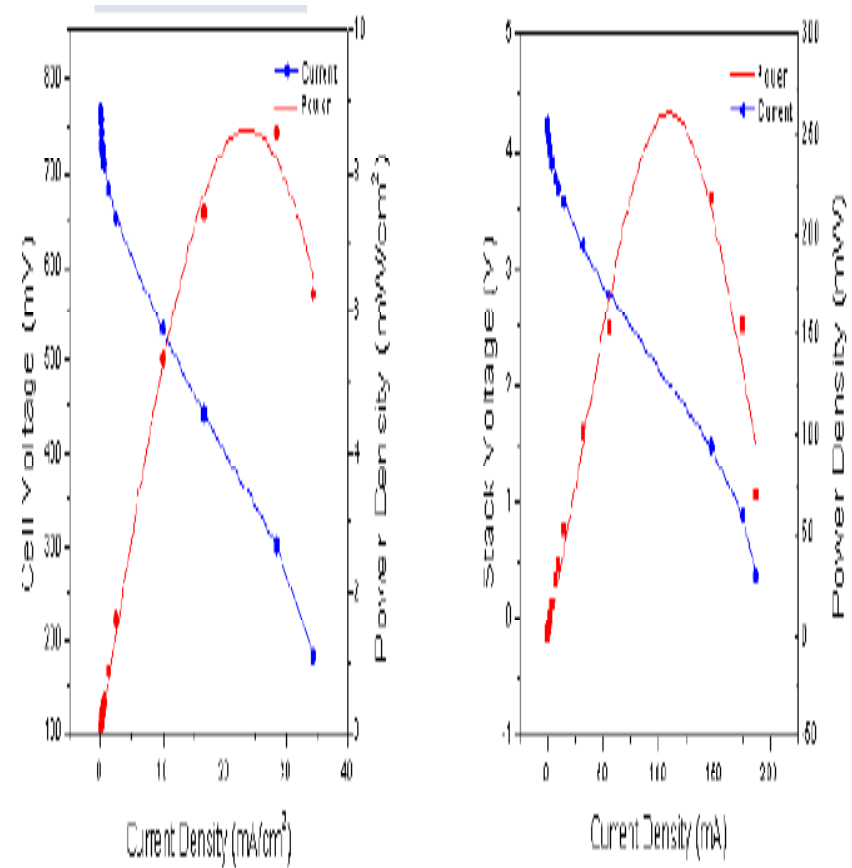

Graph 1: Performance of a single and six cell Bio battery prototype

The single cell type bio battery prototype has a power density of approximately 10 mili wat per square $\mathrm{cm}$ at the current density of $25 \mathrm{~mA}$ per square $\mathrm{cm}$ providing voltage of about $800 \mathrm{mV}$. While the six cell stack has apower density of approximately 0.25 mili watt per square $\mathrm{cm}$ at the current density of $125 \mathrm{~mA}$ per square $\mathrm{cm}$ providing voltage of about 2 volts.

Rapid progress has led to state of the art power and current densities of $9 \mathrm{~mW} / \mathrm{cm} 2$ and $35 \mathrm{~mA} / \mathrm{cm} 2$.

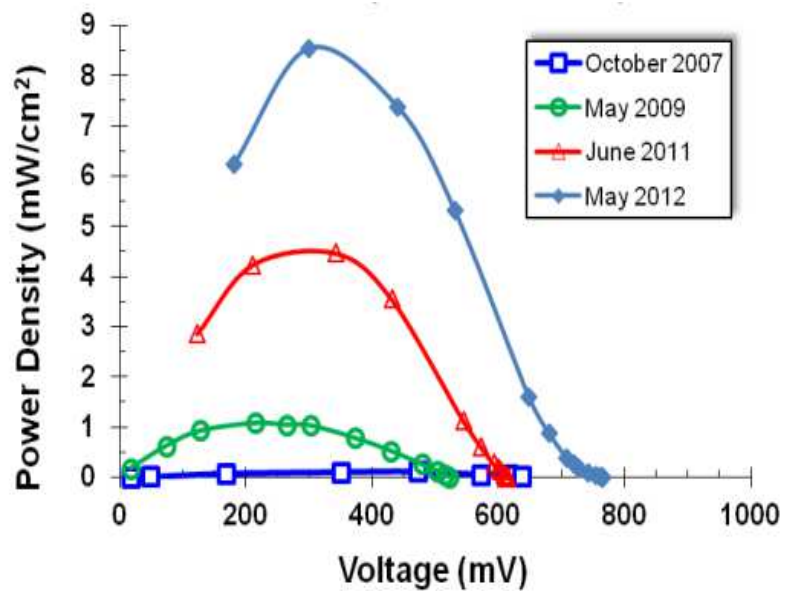

Graph 2: Progress of performance
The Bio battery has greater than six months shelf life at $+55^{\circ} \mathrm{C}$ (results from 6 test cells). Significant increase over enzyme in free solution (denatured at $40^{\circ} \mathrm{C}$ ).. This storage and operating performance is shown in the graphs below.

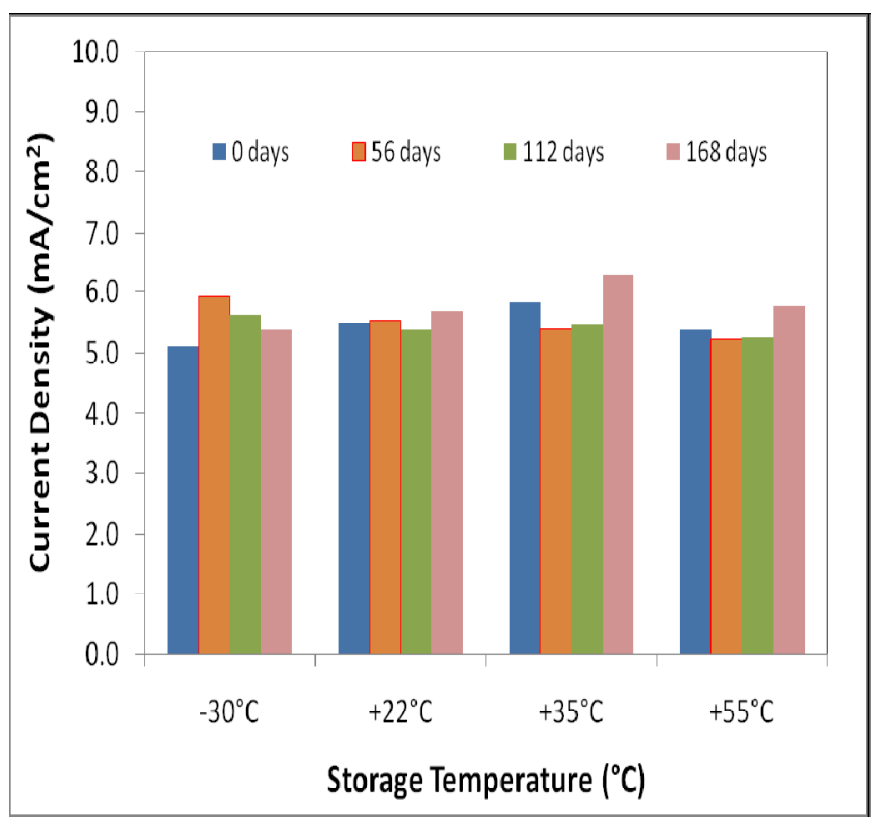

Graph 3: Temperature Vs Current density of battery

Devices ( 3 cells) show stable current $(>1.5 \mathrm{~mA} / \mathrm{cm} 2)$ over 72 hrs continuous operation with $160 \mu \mathrm{L} / \mathrm{min}$ of fuel recirculation. The current density versus operating time graph is shown in the graph above.

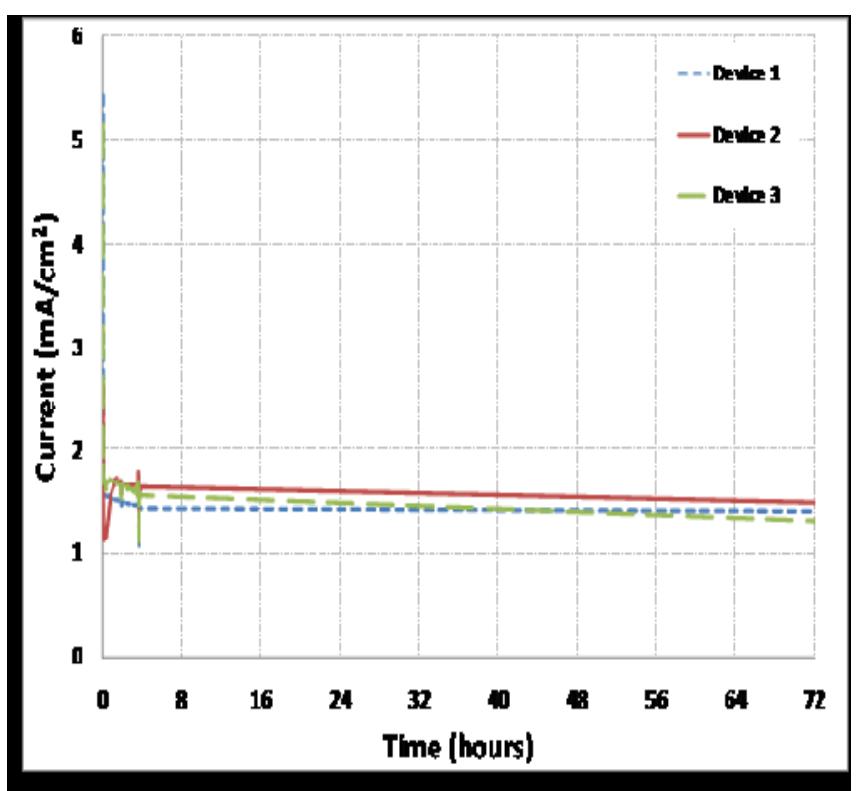

Graph 4: Performance with respect to Shelf life 
The bio battery Shows robust, repeatable, and reliable performance and stable operation from $-30^{\circ} \mathrm{C}$ to $+55^{\circ} \mathrm{C}$ for $>6$ months.

The performance of a bio battery can be understood by analyzing it with the help of an application demo.The following example shows a Bio-Battery Powering Microprocessor and LCD.

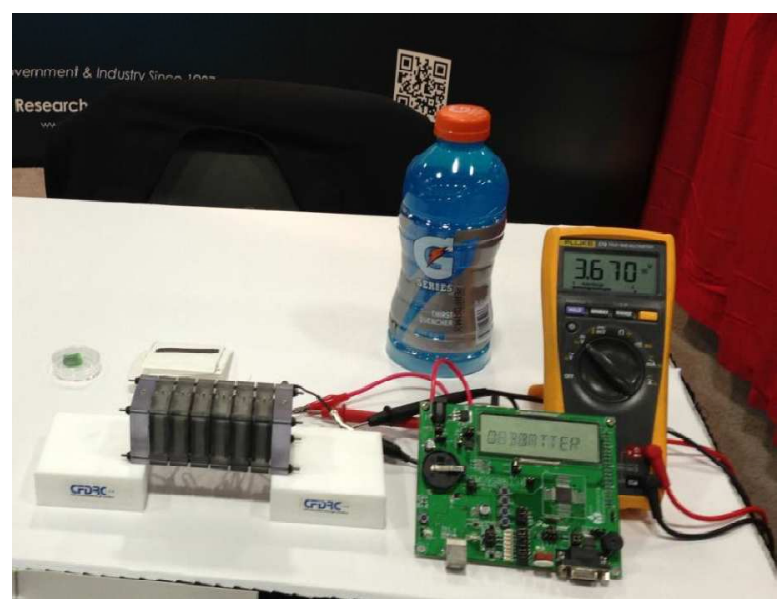

Fig -16: Microprocessor and LCD powered by bio battery

The open circuit voltage here is $>4.0 \mathrm{~V}$, Short-Circuit Current is $>125 \mathrm{~mA}$. The load voltage is $\mathrm{V}>2.0 \mathrm{~V}$ and current is approximately0.5mA while the power is $1 \mathrm{~mW}$.This application needs $5 \mathrm{~mL}$ of glucose fuel is sufficient for $>100$ hrs operation Another example shows Sensor and Wireless Transmitter running on a bio battery

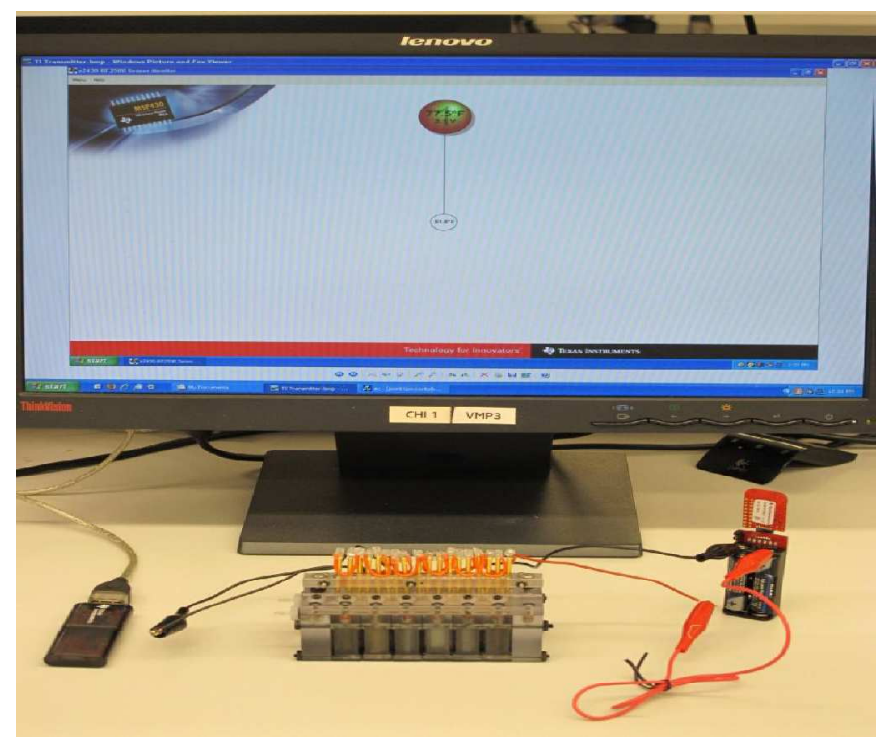

Fig -17 Sensor and Wireless Transmitter running on a bio battery
Temperature sensor with $2.4 \mathrm{GHz}$ radio attached powered by 6-cell Bio-Battery Stack Bio-Battery. It wirelessly transmits data to computer (temperature and voltage). Average power draw is $5 \mathrm{~mA}$ (peak $20 \mathrm{~mA}$ ) at $3.0 \mathrm{~V}$. It transmits every $1 \mathrm{sec}$ allows $\sim 1.5-2 \mathrm{hrs}$ operation with Bio-Battery. Transmitting every $60 \mathrm{sec}$ would allow $\sim 100 \mathrm{hrs}$ operation.

The new Prototype of bio batteries id developed in March 2013 .It is a 5W Prototype with 15-Cell Graphite Stack. This prototype is as shown in the figure below
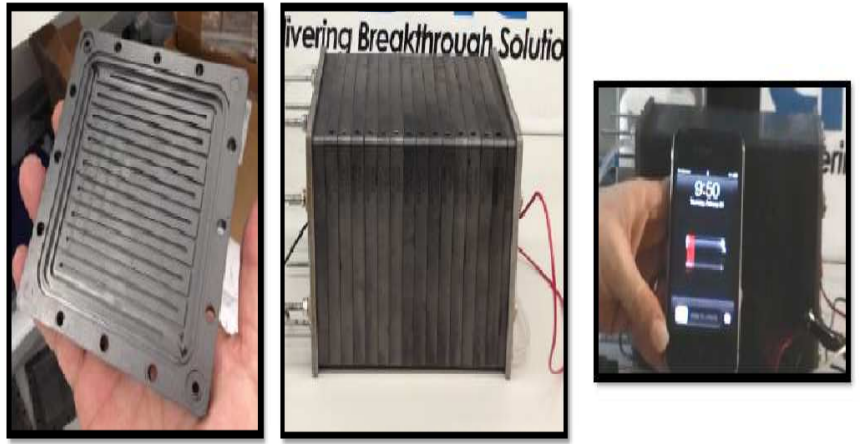

Fig -18: 15 cell stack bio battery

This 5W Prototype with 15-Cell Graphite Stack Designed and fabricated with graphite bipolar plate configuration. This Stack provides $5 \mathrm{~V}$ at $1 \mathrm{~A}(5 \mathrm{~W})$.It is Fitted with USB connector and demonstrated powering electronic devices and recharging an iPhone.[8]

\section{CONCLUSIONS}

\subsection{Conclusion}

The Bio batteries are High performing, stable, and reproducible enzymatic fuel cell technology developed over last 5 years. The Scaled-up demonstration of Bio-Battery powering electronic circuit (performed at both Power Sources and Army Science Confs). Fully-integrated Bio-Battery charging prototypes are already developed. Funding secured from multiple Department of Defense (DOD) agencies for multiple target applications over the next 3-5 years.

While many exciting announcements have been made in the field of bio-batteries, it may be some time before we see them replacing nickel-cadmium, lithium-ion or the several other types of traditional batteries. Even so, the small, flexible, longlasting and environmentally friendly battery technologies discussed here show the great possibilities researchers see in bio-batteries, especially for the field of medicine The technology generates electricity by turning shredded paper into sugar which in turn is used as fuel. If brought to market, 
the innovation could allow the public to top up the power of their mobile devices using waste material.

Compared to conventional batteries, such as lithium batteries, bio-batteries are less likely to retain most of their energy. This causes a problem when it comes to long term usage and storage of energy for these batteries. However, researchers are continuing to develop the battery in order to make it a more practical replacement for current batteries and sources of energy.

The bio-batteries are environmentally friendly as they did not use harmful chemicals or metals. . With that in mind, scientists seem to be exploring every possible option in bio-battery and fuel-cell technology.

They serve as a new form of energy that is proving to be environmentally friendly, as well as successful, in producing and reserving energy. Although the batteries are still being tested before being commercially sold, several research teams and engineers are working to further advance the development of these batteries.

\subsection{Advantages}

A significant advantage that bio-batteries have in comparison to other batteries is their ability to allow an instant recharge.In other words through a constant supply of sugar, or glucose, bio batteries are able to continuously keep themselves charged without an external power supply with high fuel flexibility like sugar, alcohol, diesel, ethanol,blood etc

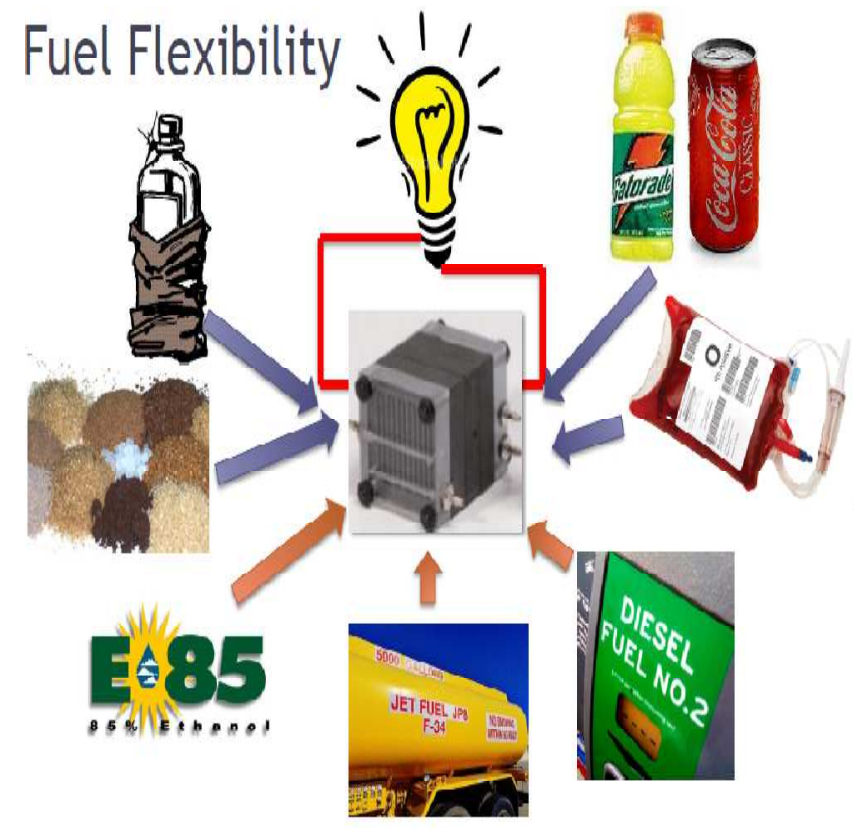

Fig -19: Different fuels used in Bio batteries
Other advantages include high energy density, size/weight, instant recharge, flexible shape, renewable biocatalysts, room temperature operation, readily available fuel source.It can be an implantable power source with flexible paper based prototypes. This is an Government and IR\&D funded research Since 2004 . Bio batteries are also a source of non-flammable, and non-toxic fuel. This provides a clean alternative renewable power source.[9]

\subsection{Future Scope}

Improved design and performance leads to $50 \mathrm{X}$ higher volumetric power density over existing prototype .The longerterm goal in this area is to further enhance performance to ultimately develop batteries suitable for notebook computers and other mobile devices. While many technological challenges still remain, Bio Battery has great potential as a next-generation energy device. Advantages include its excellent harmony with the environment as a product fueled by a carbohydrate (glucose) having high energy density. Sony will continue to work toward the commercialization of this technology in the near future, initially for use in toys and other low-power products.

Bio-batteries have a very bright future ahead of them as test productions and research have been increasing over recent years. They serve as a new form of energy that is proving to be environmentally friendly, as well as successful, in producing and reserving energy. Fully-integrated demonstrations are to be executed in close collaboration with customer, for relevant applications.[10]

\subsection{Applications}

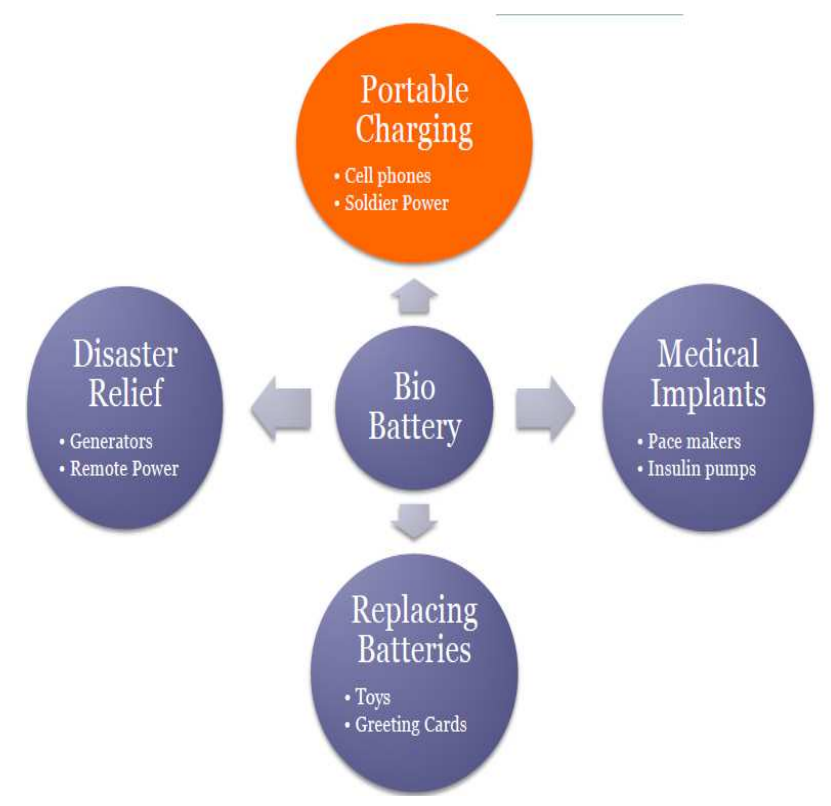

Fig -20: Applications of Bio batteries 
Bio batteries find applications in various fields like Miltary and commercial applications,Medical field,Consumer Electronics.In Miltary applications it is used for Soldier portable power, unmanned chem/bio detection (large insects), MAVs, remote surveillance (tree-sap), etc

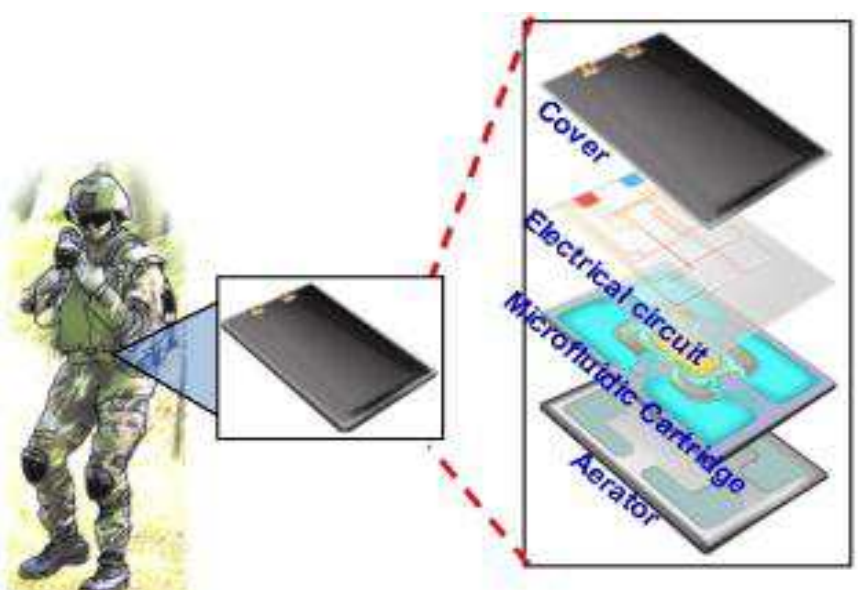

Fig -21: Miltary application of Bio battery

In medical field Paper bio battery could be used to power medical devices like hearing aid \& pacemakers Sony used its sugar bio battery to power music play back on a memory type walkman. Using a miniature bio battery enabled to test the blood insulin level of diabetic patient.

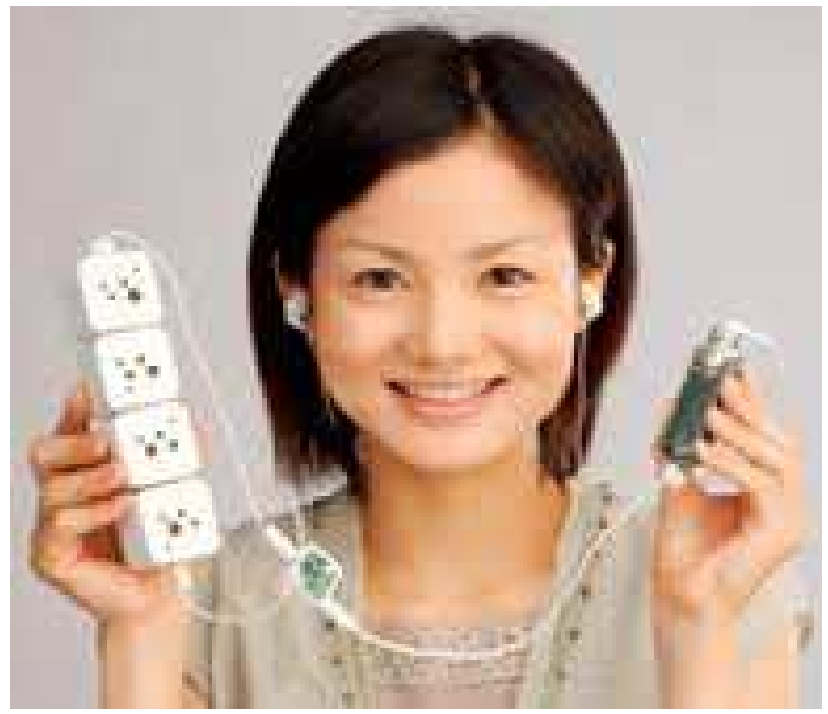

Fig -22: Walkman powered by a Bio battery

The bio batteries can be implanted in on any living body for the purpose of medical devices implantation or sensing application etc

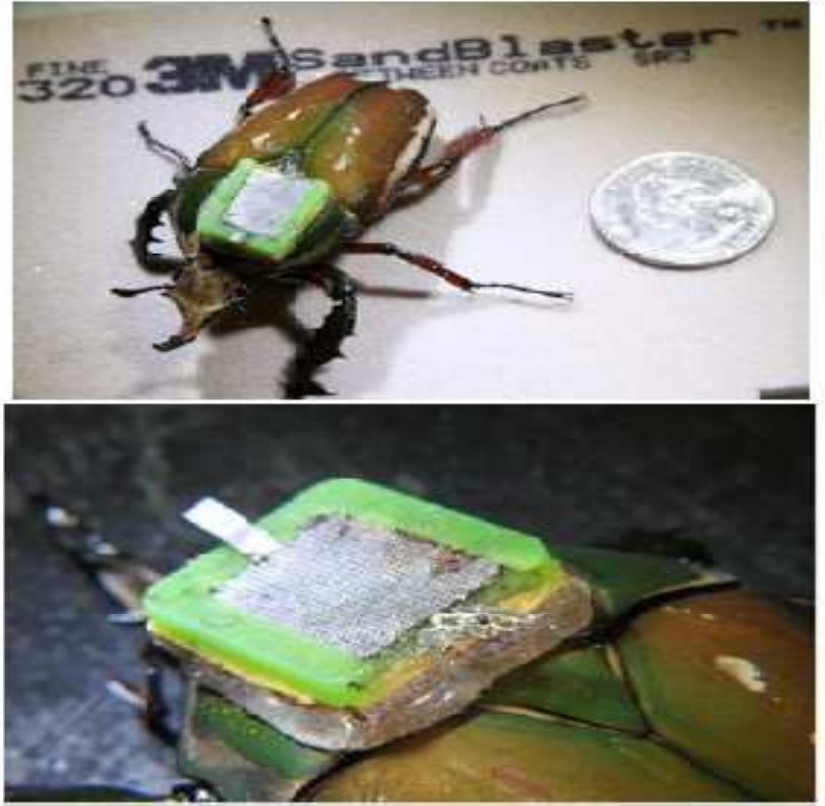

Fig -23: Bio Battery implanted on a Beetle

Bio Battery can be used to power ISR functions and recharge battery. Power source for next generation helmets, with integrated sensors containing flexible bio battery integrated onto helmet Thus this bio battery have made itself useful for numerous applications keeping the environment safe and intact with its advantages and hence it can be called as 'The fuel of Next generation'.

\section{REFERENCES}

[1]. Www..fespa.com/news/blogs/laurel.../photosynthesis-biobatteries.html

\section{[2].INHABITAT, 2007:}

http://www.inhabitat.com/2007/09/04/sony-biobattery-runsentirely-on-sugar/.

[3]. http://nanotechwire.com/news.asp?nid $=4102, \mathrm{NIH}$ selects Purdueto use phi29 DNA packaging motor for national nanomedicine development center.

[4].http://www.sony.net/SonyInfo/News/Press/200708/07074E /index.html,Energy Environ. Sci., 2, 133 (2009).

[5].www.sciencedaily.com/releases/2013/07/130717051733.ht $\mathrm{m}$

[6].http://www.qrg.northwestern.edu/projects/vss/docs/power/ 2-how-do-batteries-work.htmln

[7].A. M. Kannan, V. Renugopalakrishnan, S. Filipek3, P. Li, G. F. Audette,and L. Munukutla Journal of Nanoscience and Nanotechnology Vol.9, 1665-1678, 2009

[8]. D. Yamaguchi, et al, Meet. Abstr. - Electrochem. Soc. (2010), in press

[9] M.B.Fischback, J.K.Y oun, X.Zhao, P.W ang, H.G.P ark, H.N. Chang, J.Kim, and S.Ha, "Electroanalysis "18, 2016 (2006). 
[10]Http://advantage-

environment.com/uncategorized/cellulose

-based-batteries/ 